$\begin{array}{cc}\text { ACADEMIA ROMÂNĂ } & \text { Rev. Roum. Chim., } \\ \text { 2020, 65(9), 815-823 }\end{array}$

\title{
ELECTROCHEMICAL SYNTHESIS AND CHARACTERIZATIONS OF NEW NANOCOMPOSITE ELECTRODEPOSITION ON Co67Cr29W4 ALLOY SUBSTRATE
}

\author{
Florina BRANZOI \\ Institute of Physical Chemistry "Ilie Murgulescu”, 202 Splaiul Independenței, Bucharest - 060021, Roumania
}

Received April 23, 2020

\begin{abstract}
In this study, galvanostatic electrodeposition techniques were employed for the achieved of new composite polymer: polypyrrole - sodium dioctyl sulfosuccinate/poly N-ethylaniline (PPY-AOT/PNEA) coatings on the Co67Cr29W4 alloy electrode surface. The PPYAOT/PNEA coating has been synthesized on the Co67Cr29W4 alloy electrode by galvanostatic deposition from aqueous solutions 0.1 M NEA, 0.1M PY, 0.01 M AOT and $0.5 \mathrm{M} \mathrm{H}_{2} \mathrm{SO}_{4}$ solution at various current densities $\left(1 \mathrm{~mA} / \mathrm{cm}^{2}, 2 \mathrm{~mA} / \mathrm{cm}^{2}\right.$ and $\left.8 \mathrm{~mA} / \mathrm{cm}^{2}\right)$ in different molar ratio. The sodium dioctyl sulfosuccinate (AOT) as a dopant ion used in electropolymerization process be able to a significant influence on the electrochemical activity of the composite polymer. The polymeric composite coatings were characterized by cyclic voltammetry (CV), electrochemical impedance spectroscopy (EIS), and scanning electron microscopy (SEM) techniques. The results denoted that the electroactive behaviors of the composite polymer mainly depend on the molar ratio of monomers, the applied density current and times of electrodeposition. It has been established that the cobalt based alloy substrate had a meaningful influence on the electrochemical activity of the polypyrrole and poly(N-ethylaniline) composite films and that as in the existence of polymeric film, anodization of these modified electrodes obtained in constitution of an oxides complex film and polymeric layers together. All of the composite films were a very promising electrode material for application in supercapacitor, corrosion protection coatings or sensor employments.
\end{abstract}
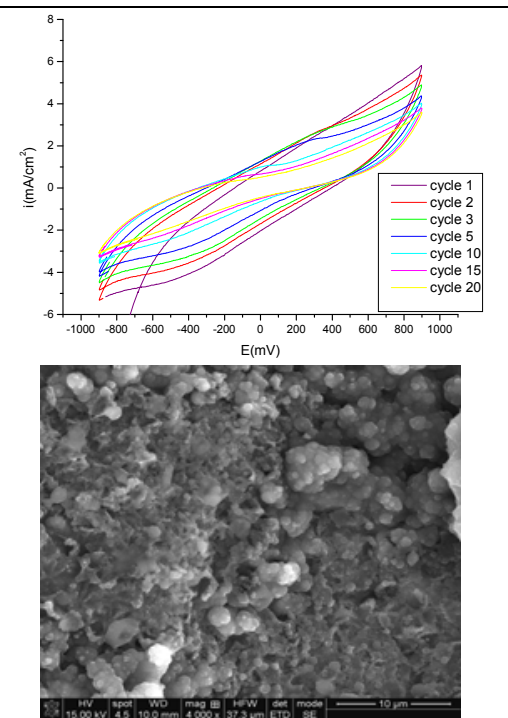

\section{INTRODUCTION}

In last years, conducting polymers have attracted significant consideration in scientific and technological domains according to their electrical, thermal, environmental, optical, chemical and biological characteristics, the ease of their obtaining and their wide applicability. Conducting polymers are as well intriguing molecular structures due their capability to considerably modify properties when activated by an electric signal. ${ }^{1-9}$ These new materials give interesting promises for a large domain of new implements as membranes, solar cells, batteries, sensor, capacitors, nanoelectronics and corrosion protection coatings. Electroactive polymers with different oxidation states keep drawing the interest of numerous researchers due to their diverse electrochemical properties, which make them responsible for use in a large diversity of practices. ${ }^{6-13}$ The electrodeposition of conducting polymers over active surface of metals and alloys has been a subject of numerous researches for a wide field of new materials. The polymeric composites formed of conducting polymers have a number of special properties as enhanced chemical stability, thermostability and high electroactivity. ${ }^{4-18}$

\footnotetext{
${ }^{*}$ Corresponding author: fbrinzoi@chimfiz.icf.ro
} 
The obtaining of new polymeric films from various monomer molecules was achieved to improve the physico-chemical properties of polymer coatings, to enhance for protection time, for increased adherence and to better the electrochemical properties. Though, by accomplished adequate of electropolymerization of composite film, it is practicable to increase the mechanical and protective properties of the composite in scope to be employed as a very good anticorrosive film in different aggressive environments. Numerous studies were accomplished relevant on the protective behaviour of conducting polymers on various metallic surfaces. ${ }^{9-20}$ This can be perfected by achievement of organic composite which have significant applications in many domains of materials that they are easy to acquire and pliable to project at large scale. ${ }^{16-26}$ It was indicated that the electrochemical and physical properties of polymers are considerably affected by the kind of dopant and electrolyte over the polymerization process. Conducting polymers including two compounds can be obtained as co-polymers, composites, bilayers or mixtures. Generally, this is done for enhancement of physical, chemical, mechanical and electrical properties of homopolymers. Polymers as polypyrrole and polyaniline were analyzed and continue to be studied very actively, especially since these polymers can be very conveniently obtained by simple electrochemical method. ${ }^{8-10,17-26}$ Since the oxidation potential of aniline $(0.8 \mathrm{~V}$ vs. SCE) and pyrrole $(1.2 \mathrm{~V}$ vs. SCE) are almost, we consider that simultaneous oxidation and co-deposition of polyaniline and polypyrrole is eventual by changing the applied potential. The kind of the working electrode performs a significant role in the electrodeposition of polymeric films. Thermodynamic investigation estimates that the metal will begin to dissolve right before the electropolymerization potential of the monomer is reached. ${ }^{6-14,25-26}$ So, the suitable conditions are to be establishing where the passivation of the metal takes place without any barrier to electropolymerization. This work is a continuation of previous work on the obtaining and examined of the composite films doped with the anionic surfactant that were electrodeposited on the Co67Cr29W4 alloy substrate by electrochemical method. In this study is presented electrochemical synthesis of composite films from conducting polymerspyrrole and N-ethylaniline and sodium dioctyl sulfosuccinate as dopant. The electrochemical characterization of these polymeric films has been realized by cyclic voltammetry, electrochemical impedance spectroscopy and the surface morphology investigation by scanning electron microscopy (SEM) methods.

\section{EXPERIMENTAL}

\section{Materials and Instruments}

All chemicals have been reagent grade and used as received without further purification, N-ethylaniline (NEA), pyrrole (PY), dioctyl sulfosuccinate sodium (AOT) have been provide from Fluka $(>99 \%)$, acid sulfuric $\left(\mathrm{H}_{2} \mathrm{SO}_{4}\right)$ was received from Merck (98\%). In all experiments, the solutions were prepared by using double distilled water: NEA $0.1 \mathrm{M}$, AOT 0.01M, PPY 0.1M and $0.5 \mathrm{M} \mathrm{H}_{2} \mathrm{SO}_{4}$.

The electrodeposition was achieved by galvanostatic methods: at current densities $1 \mathrm{~mA} / \mathrm{cm}^{2}, 2 \mathrm{~mA} / \mathrm{cm}^{2}$, and $8 \mathrm{~mA} / \mathrm{cm}^{2}$ in varied molar ratio for NEA and PY-AOT and the deposition was realized at a period time of 10,20 and $30 \mathrm{~min}$. The electrochemical behavior of composite films has been investigated in a solution of $0.5 \mathrm{M} \mathrm{Na}_{2} \mathrm{SO}_{4}$.

The obtaining and characterization of these polymeric films were accomplished by employment of a single compartment cell with the conventional three electrodes set up at room temperature. The cell was connected to a VoltaLab potentiostat coupled to a PC running VoltaMaster software. A saturated calomel electrode (SCE) was employed as the reference electrode and a platinum gauze as an auxiliary electrode. The working electrode has been a Co67Cr29W4 alloy disk with a surface area of $0.2 \mathrm{~cm}^{2}$, which is a special metallic biomaterial.

\section{Characterization of the polymeric film}

The electrochemical properties of the polymeric films have been assessed by cyclic voltammetry (CV), electrochemical impedance spectroscopy (EIS) and scanning electron microscopy (SEM). The electrochemical investigation of the PPY-AOT/PNEA was performed in $0.5 \mathrm{M} \mathrm{Na} \mathrm{Na}_{4} \mathrm{SO}_{4}$ cycling aqueous solutions for comparison and that the dopant anion of the polymeric films is the same with the anion of the cycling solution. Thirty successive potential scans were effectuated for modified electrodes and they have been cycled in the potential domain of $-900 \mathrm{mV}$ to $+900 \mathrm{mV}$ with a scan rate of $20 \mathrm{mV} / \mathrm{s}$. The impedance tests accomplished using a VoltaLab 40 potentiostat/galvanostat in the frequency range of $100 \mathrm{kHz}$ to $10 \mathrm{mHz}$ with an $\mathrm{AC}$ wave of $5 \mathrm{mV}$ (peak-to-peak) overlaid on a DC bias potential and the impedance results were achieved at a rate of 10 points per decade change in frequency. The Scanning Electron Microscopy (SEM) was utilized to analyze the surface morphology by JEOL JSM-5500LV microscope working at $30 \mathrm{kV}$.

\section{RESULTS AND DISCUSSION}

The synthesis and charateristics of the pyrrole (PY) and N-ethylaniline (NEA) exhibiting itself as a novel material in the domain of conducting polymers were intensive elaborated [4-9]. It was demonstrated that alongside with a series of other parameters, the anions incorporated in the 
positively charged polymer for charge compensation affect the growth evaluate, the morphology of the obtained polypyrrole films and the rate and measure of the electrochemical response. The electrochemical redox mechanism of PPY is influenced by the anions since of the movement of anions and protons in the polymer accompanying the redox of PPY. Hence, the kind of the anions plays a significant role in attributing the properties of the polymeric films.

In Figure 1 the cyclic voltammograms are presented in an aqueous solution of $0.5 \mathrm{M} \mathrm{Na}_{2} \mathrm{SO}_{4}$ of polypyrrole - dioctyl sulfosuccinate sodium (PPY-AOT) film electrodeposited on Co67Cr29W4 alloy substrate. This polymeric film was obtained by electrodeposition using the galvanostatic method at a current density of $1 \mathrm{mAcm}^{-2}$ for $10 \mathrm{~min}$. From the investigation of Figure 1, it can be observed that, at the first cycle on the anodic potential scan an anodic current peak that is high and wide is achieved while at the reverse potential scan, a broad cathodic current peak is remarked. This anodic peak reveals the oxidation processes that occurs in polypyrrole film at the anodic scan of the potential. The separation potential range $\left(\Delta \mathrm{E}_{\mathrm{P}}\right)$ among the anodic and cathodic peaks is wide enough and reveals the case that, at the electrode surface quasi-reversible processes occur. Furthermore, through increasing the number of cycles, the accomplished cyclic voltammogram has a changed form in comparison with the first cyclic. It can be noticed that over the anodic branch of the voltammograms the anodic oxidation peak has a reduced height and it is moved to a more positive potential. This comportment is owing to the establishment of a complex oxides film which impeds the redox processes of the polypyrrole film and so, the anodic oxidation current decreases. On the catodic bough, the cathodic peak is reduced in the same potential range.

The oxidation and the reduction peaks that exhibit at the polypyrrole film cycling can be described by the following mechanism:

$$
\begin{gathered}
\mathrm{PPY}^{+} \mathrm{A}^{-}+\mathrm{e}^{-}+\mathrm{C}^{+} \leftrightarrow \mathrm{PPYA}^{-} \mathrm{C}^{+} \\
\mathrm{PPYA}^{-} \mathrm{C}^{+}-\mathrm{e}^{-}+\mathrm{X}^{-} \leftrightarrow \mathrm{PPY}^{+} \mathrm{A}^{-} \mathrm{C}^{+} \mathrm{X}^{-} \\
\mathrm{PPY}^{+} \mathrm{A}^{-} \mathrm{C}^{+} \mathrm{X}^{-}+\mathrm{e}^{-} \leftrightarrow \mathrm{PPYA}^{-} \mathrm{C}^{+}+\mathrm{X}^{-}
\end{gathered}
$$

where: $\mathrm{A}^{-}$represents the dopant anion, $\mathrm{C}^{+}$and $\mathrm{X}^{-}$ represent the cation and anion, respectively, from the supporting electrolyte.

The shape of the voltammetric curve also evidences this redox mechanism. The experimental results show that the great surfactant anions suport redox processes, which are faster and more reversible than those corresponding to normal polypyrrole electrodes. In event while in polypyrrole films doped by typical, small anions (e.g. $\mathrm{SO}_{4}{ }^{2-}$ ), the charge compensation is provided by taking of the anions over oxidation and the liberation of the same anions during reduction, in the polypyrrole films obtained in the presence of large surfactant anions, the charge compensation reveals to imply incorporation of cations where as the large anions are not easily released from polymer matrix. The frequency response of polypyrrole films was elaborated in the existence of $\mathrm{SO}_{4}{ }^{2-}$ in the potential zone of relevace for the study of the insulator - conductor transition.

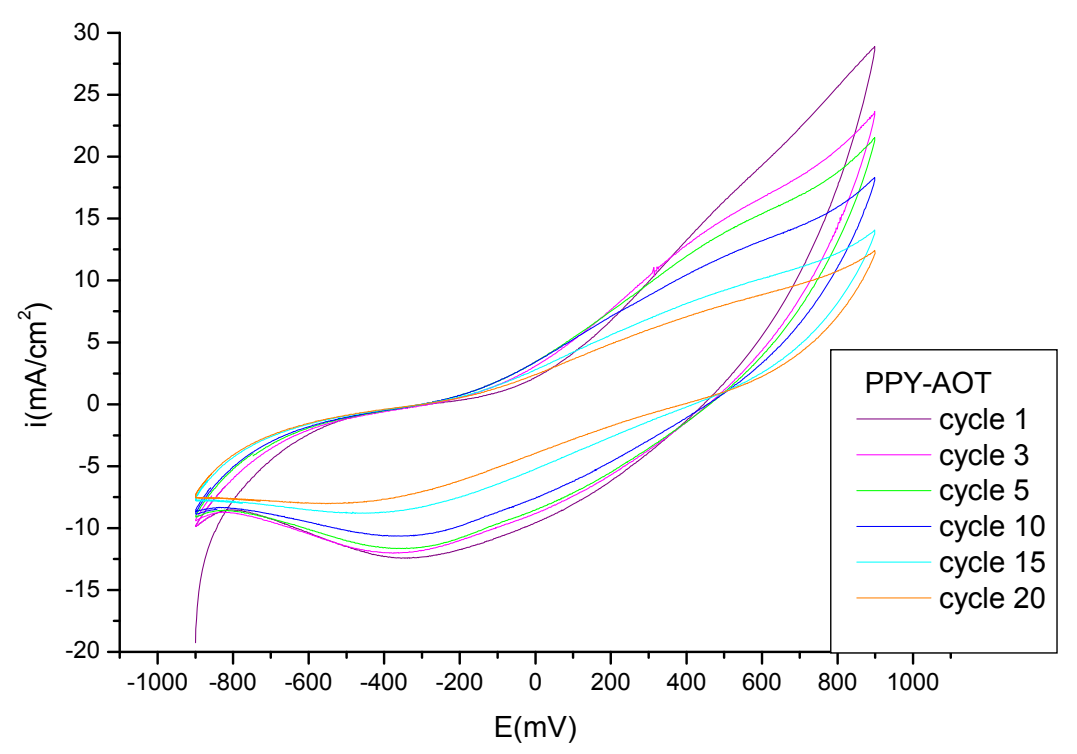

Fig. 1 - Cyclic voltammograms in solution of $0.5 \mathrm{M} \mathrm{Na}_{2} \mathrm{SO}_{4}$ of PPY -AOT film electrodeposited on Co67Cr29W4 alloy substrate. 
In Figure 2 the cyclic voltammograms are presented in an aqueous solution of $0.5 \mathrm{M} \mathrm{Na}_{2} \mathrm{SO}_{4}$ of poly-N-ethylaniline (PNEA) film electrodeposited on Co67Cr29W4 alloy substrate. This polymeric film was realized by electrodeposition utilizing the galvanostatic method at a current density of $2 \mathrm{mAcm}^{-2}$ for $10 \mathrm{~min}$. Through increasing anodic potential scan, the oxidated forms of polyNethylaniline are achieved and on the anodic branch of the voltammogram the oxidation peaks appear. At the reverse potential scan, the reduction processes occurs and on the cathodic bough of voltammograms, the reduction peaks arise. Once the number of cycles increase, the shape of voltammograms changes. Examining the Figure 2 it can be seen that once the number of cycles increase, decrease of the peak heights, and a displacement of the anodic peaks to more electropositive values and of the cathodic peaks to more electronegative values eventuate.

The obtaining of polypyrrole/ dioctyl sulfosuccinate sodium (PPY-AOT) - poly N-ethylaniline composite films on Co67Cr29W4 alloy electrode has been analyzed in $\mathrm{Na}_{2} \mathrm{SO}_{4}$ aqueous solutions using galvanostatic technique. It was noticed that the structure and the morphology of the films were influenced by the feed ratio of monomers $(\mathrm{N}$ ethylaniline and pyrrole) and the applied current densities $\left(1 \mathrm{~mA} / \mathrm{cm}^{2}, 2 \mathrm{~mA} / \mathrm{cm}^{2}\right.$ and $\left.8 \mathrm{~mA} / \mathrm{cm} 2\right)$ in different molar ratio $(1: 1,3: 5,4: 5$ and 5:5). The achieved composites also indicated meaningful changes in electrochemical comportment when compared with the homopolymers.

Figure 3 shows the cyclic voltammetric behaviour of PPY-AOT/PNEA/Co67Cr29W4 alloy electrode in 5:4; 3:5 and 5:5 molar feed ratio of monomers. By investigation of Figures $3 \mathrm{a}, \mathrm{b}$ and $\mathrm{c}$, it can be established that in comparison with the homopolymers, the obtained composite has an intermediate comportment which evidenced the constitution of a new material composite. The influence of AOT, as an anionic dopant, on the electropolymerization of the polymer in aqueous solutions has been examined and it can be appreciated that AOT increases the conductivity of the polymer. The analysis of voltammograms suggests that the great surfactant anions influence redox processes, which are faster and more reversible than those related to normal polypyrrole electrodes. Electrochemical deposition of polypyrrole - dioctyl sulfosuccinate sodium (PPY-AOT) and poly-N-ethylaniline (PNEA) from various precursor solutions determines homogeneous and adherent black films. The polymeric composites exhibit an important electroactivity in the cycling solutions and the shape of voltammograms are very similar to the potential values of the current peaks are outdated at intermediate values of the typical electrochemical responses of the homopolymers.

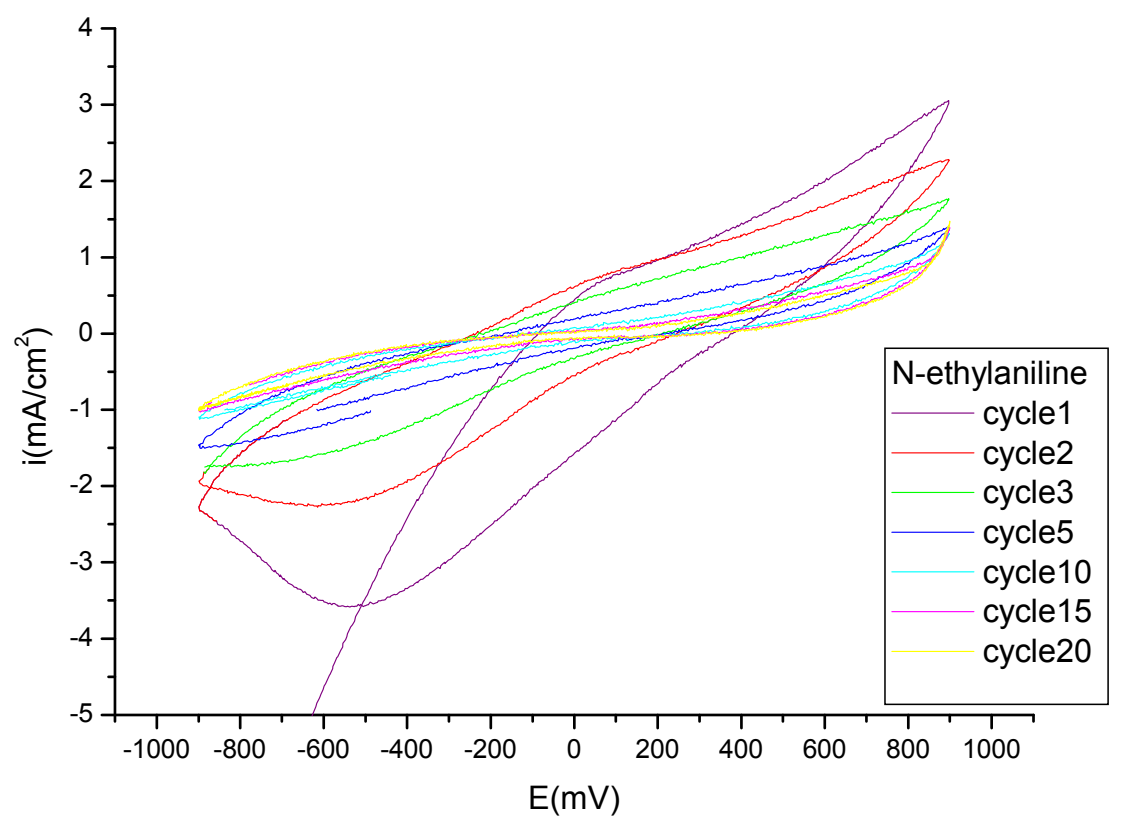

Fig. 2 - Cyclic voltammograms in solution of $0.5 \mathrm{M} \mathrm{Na}_{2} \mathrm{SO}_{4}$ of PNEA film electrodeposited on Co67Cr29W4 alloy substrate. 


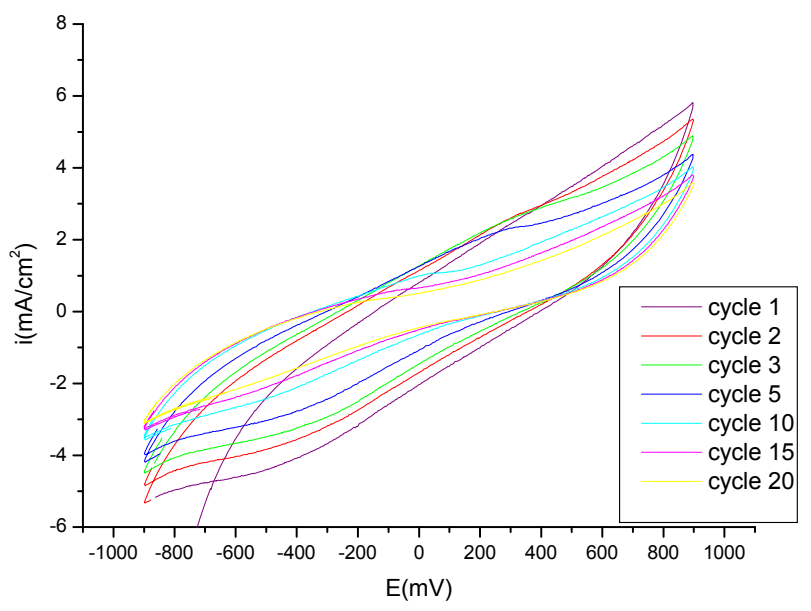

a)

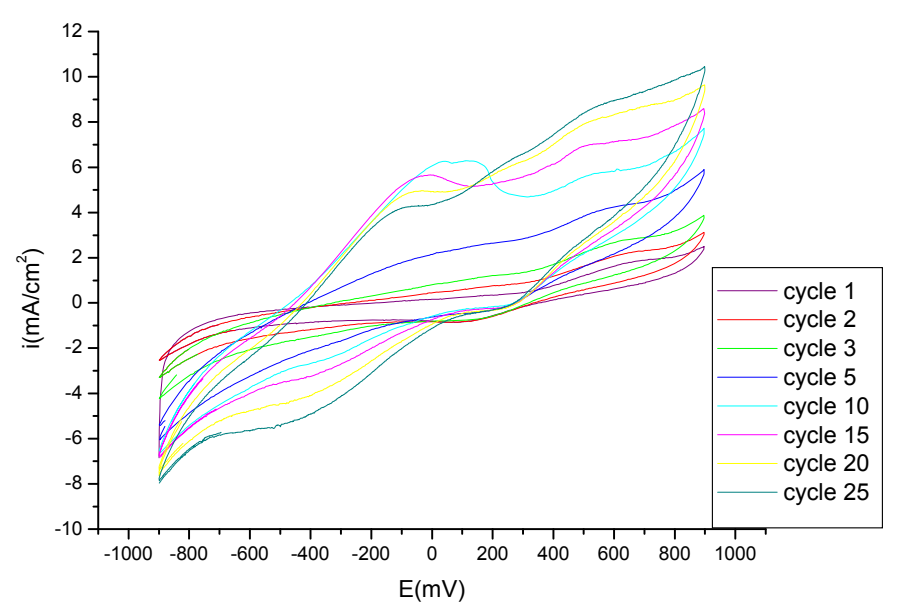

b)

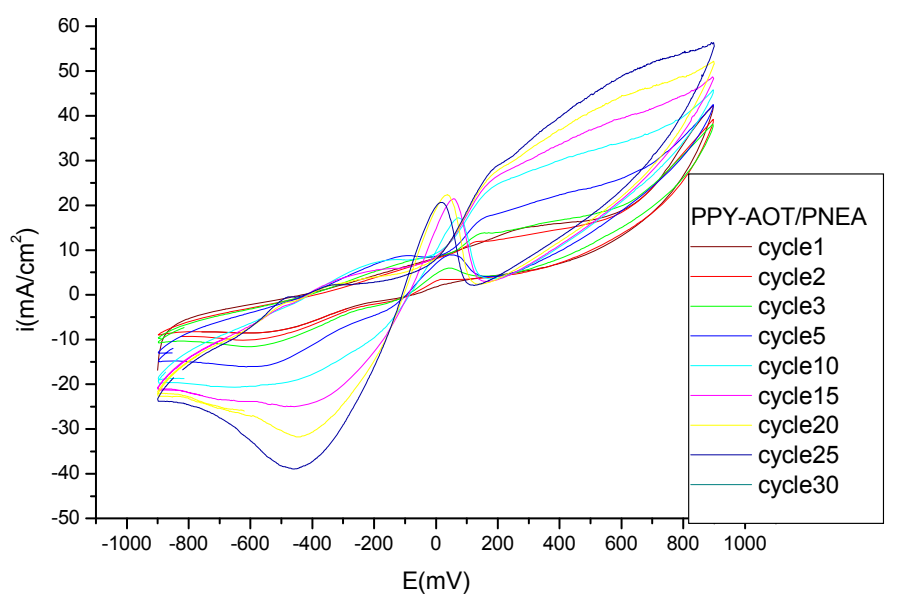

c)

Fig. 3 - The cyclic voltammograms of PPY-AOT/PNEA composite films obtained on a Co67Cr29W4 alloy electrode at different cycles in $0.5 \mathrm{M} \mathrm{Na}_{2} \mathrm{SO}_{4}$ solutions; (a) 5:4 (b) 3:5 and (c) 5:5 (PPY-AOT: PNEA) molar feed ratios.

Figure 4 are presented the cyclic voltammograms of behaviour of PPY-AOT/PNEA/Co67Cr29W4 alloy electrode in relationship to the electrodeposition time and at different cycles (cycle1 and cycle10). By examining this figure, it can be noticed that the electrochemical comportment of composite film is modified with the change of the electrodeposition time and with the number of cycles. From Figure 4a, it can be observed that, at the first cycle, the anodic and cathodic oxidation peaks of composite film accomplished for an electrodeposition time of $10 \mathrm{~min}$ are wider and higher than those achieved for electrodeposition times of 20 and $30 \mathrm{~min}$. At the first cycle, the peak potentials for PPY-AOT/PNEA composite achieved after an electrodeposition time of $10 \mathrm{~min}$ are more negative than those of PPYAOT/PNEA composite realized by electrodeposition times of 20 and $30 \mathrm{~min}$. As a result, the peak currents are less and the peak potentials more positive, considering that the redox mechanisms from the
Co67Cr29W4 surface are impeded by the composite films accomplished after the electrodeposition times of 20 and $30 \mathrm{~min}$.

From Figure $4 \mathrm{~b}$ it can be observed that the anodic and cathodic peaks of PPY-AOT/PNEA composite films achieved by electrodeposition time of 20 and $30 \mathrm{~min}$ are larger and higher than those of the PPY-AOT/PNEA composite film acquired after $10 \mathrm{~min}$ and, in the same period, are moved to more positive potentials. This comportment can be described by the fact that after ten cycles of potential scan, the porosity and the conductivity of the composite films increase with the number of cycles and, as a result, the height of the anodic and cathodic peaks raises and, as well, the potential intervals where these peaks are revealed become wider. This comportment showed that, the redox processes which occur at the electrolyte/PPY-AOT/PNEA composite film interface get intensive and more complex. 


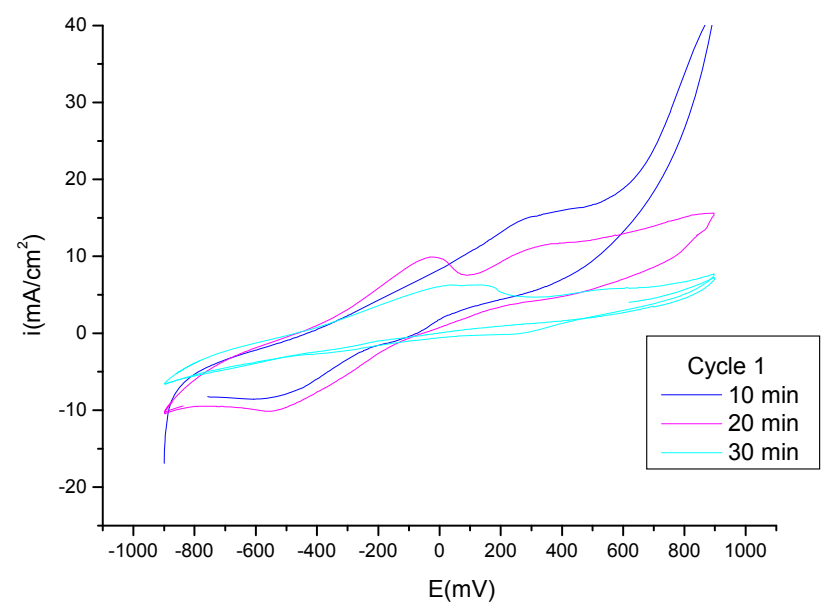

a)

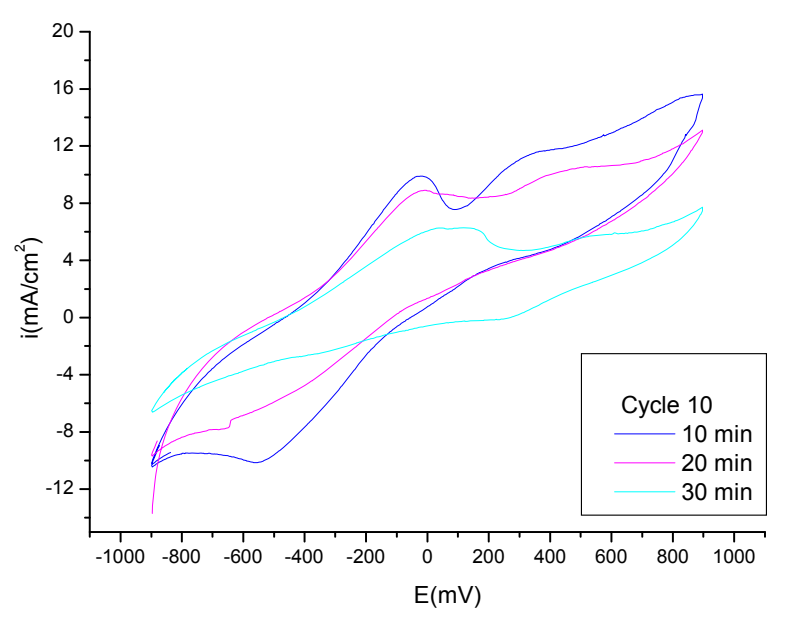

b)

Fig. 4 - The cyclic voltammograms of PPY-AOT/PNEA composite films obtained on a Co67Cr29W4 alloy electrode in $0.5 \mathrm{M} \mathrm{Na}_{2} \mathrm{SO}_{4}$ solutions at different electrodeposition times $(10,20,30 \mathrm{~min})$; (a) 1 st and (b) 10th cycles.

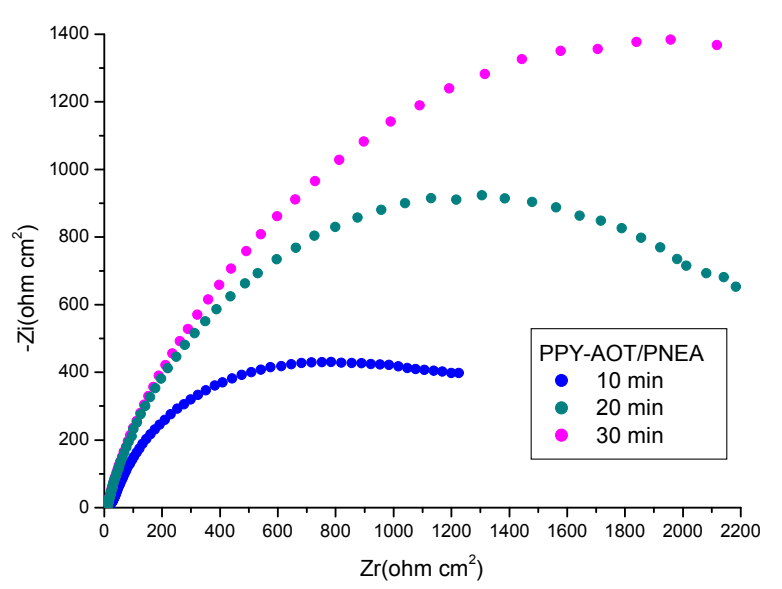

a)

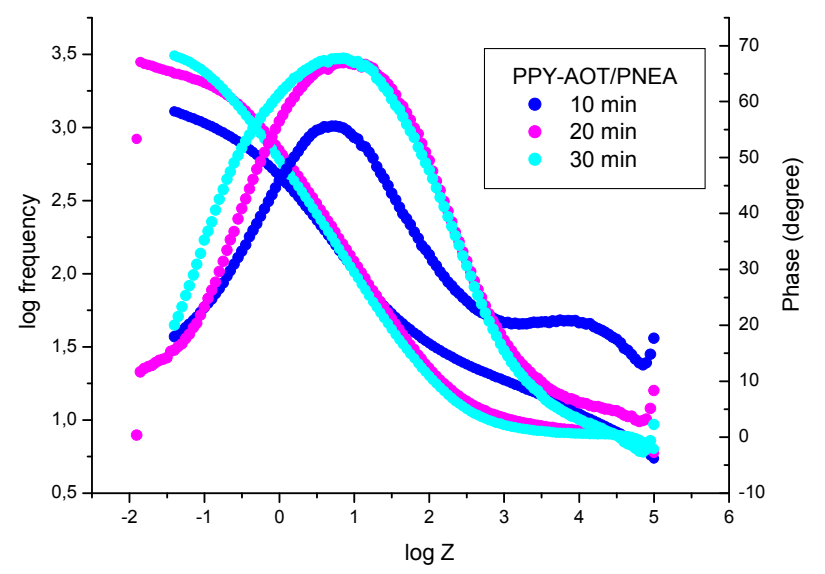

b)

Fig. 5 - The EIS plots PPY-AOT/PNEA/Co67Cr29W4 alloy electrode achieved by galvanostatic method in 5:4 molar ratio at 10,20 and $30 \mathrm{~min}$, at a current density of $2 \mathrm{mAcm}^{-2}$ in $0.5 \mathrm{M} \mathrm{Na}_{2} \mathrm{SO}_{4}$ solutions: (a) Nyquist and (b) Bode diagrams.

The electrochemical impedance spectroscopy (EIS) has been utilized to examine the comportment of the of PPY-AOT/PNEA composite films accomplished on a Co67Cr29W4 alloy electrode in $0.5 \mathrm{M} \mathrm{Na}_{2} \mathrm{SO}_{4}$ solutions at different electrodeposition times and various molar feed ratio of monomers.

Exploring the Nyquist impedance plots for the PPY-AOT/PNEA film accomplished at $10 \mathrm{~min}$, it can be noticed that, at the high, medium and low frequencies, a depressed capacitive loop is achieved. From the Figure 5, it can be remarked that with the rise of the deposition time, the capacitive loop gets wider and higher and consequently the polarization resistance has greater values, significance that the PPY-AOT/PNEA composite is homogene, dense and more adherent
(23-26). The Bode diagrams from Figure $5 \mathrm{~b}$ are in concordance with results from the Nyquist plots from Figure 5a. From Bode diagrams, it can be seen that the curve of phase angle against frequency logarithm, a fine defined maximum shows, which correlates with a relaxation time constant for every case. Therefore, for the composite film accomplished after a deposition time of $30 \mathrm{~min}$ and $20 \mathrm{~min}$, the relaxation time constant corresponds to a phase angle of approximately $70^{\circ}$, which suggests a capacitive comportment with slight diffusive trend. For the composite films obtained after $10 \mathrm{~min}$ by electrodeposition technique, the phase angles are lower, about $60^{\circ}$ which means the thickness and the adherence of composite film decreases, and the capacitive behaviour diminitions. 


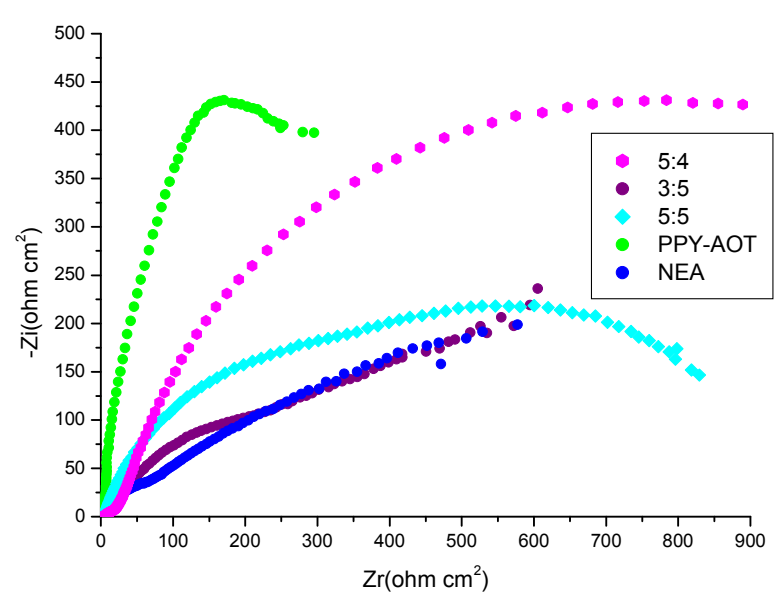

a)

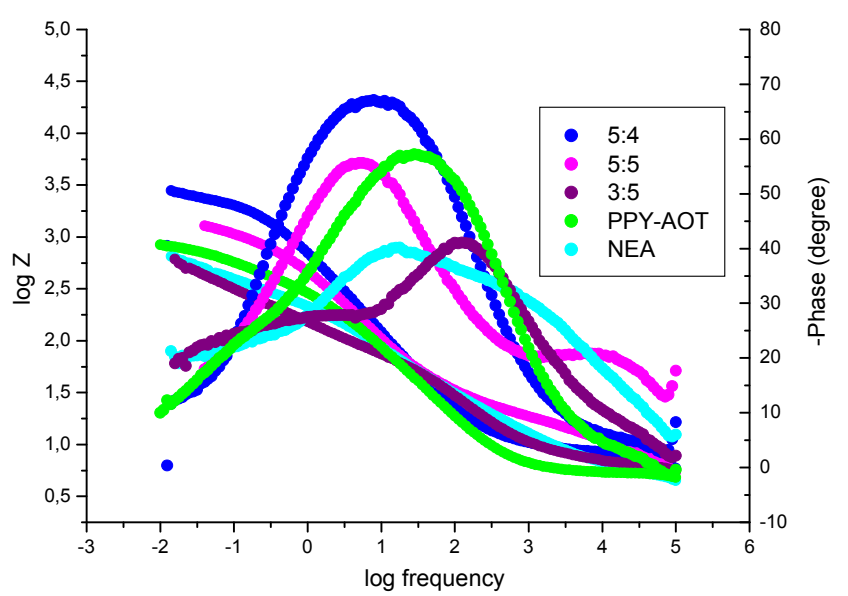

b)

Fig. 6 - The EIS plots of PPY-AOT/PNEA /Co67Cr29W4 alloy electrode achieved by galvanostatic method in molar ratio at $10 \mathrm{~min}$, at a current density of $1 \mathrm{mAcm}^{-2}$ in $0.5 \mathrm{M} \mathrm{Na}_{2} \mathrm{SO}_{4}$ solutions: (a) Nyquist and (b) Bode diagrams.

In Figure 6 are presented the Nyquist and Bode plots for PPY-AOT/PNEA, PPY-AOT, and PNEA composite films realized by galvanostatic method after an electrodeposition time of 10 in at a current density of $1 \mathrm{mAcm}^{-2}$. It can be said that in Nyquist diagrams Figure 6a, one can notice that in all the situations at high frequencies capacitive loop arise, continued by a diffusive zone $(6,12,24-26)$. The Nyquist diagram of the PPY-AOT/PNEA composite film arises among the Nyquist diagrams of PPY-AOT and PNEA film and this case demonstrates that the composite films are novel materials with various features in comparison with homopolymers. It can be observed from Figure $6 \mathrm{~b}$ on the diagrams- phase angle versus log frequency, a very well defined maximum indicates appropriate to a phase angle of about $-70^{\circ}$ for PPYAOT/PNEA (5:4 molar ratio), which represents that in this occurrence the electrode has a strong capacitive with slight diffusive tendency. For the PPY-AOT/PNEA (5:5) composite film, the time constant corresponds to a phase angle of $60^{\circ}$, for PPY-AOT $62^{\circ}$ which means a capacitive behaviour with low diffusive tendency. On the other hand, for PPY-AOT/PNEA (3:5) composite film, the time constant appears at high frequencies and corresponds to $48^{\circ}$ and for PNEA a phase angle of $47^{\circ}$ this case denotes a capacitive behaviour with low diffusive tendency $(6,12,23-26)$. Investigating the results acquired by EIS measurements, it can be said that the composite films exhibit an intermediate comportment among the properties of homopolymers and this case proves that the PPY-AOT/PNEA composite films are new materials with various properties. The new materials PPY-AOT/PNEA composite were a very promising electrode material for application in supercapacitor, corrosion protection coatings or sensor usage.

\section{Characterization of composite by SEM}

The morphology of the PPY-AOT, PNEA and PPY-AOT/PNEA composite films achieved on the Co67Cr29W4 alloy electrode substrate has been studied by scanning electron microscopy. The SEM images of PPY-AOT/PNEA, coatings electrodeposited in different conditions Co67Cr29W4 alloy are presented in Figure $7 \mathrm{c}$-d. The SEM micrograph of PPY film electrodeposited onto Co67Cr29W4 alloy surface showed in Figure 7a display homogeneous, cauliflower-like morphology obtained by microspherical grains with dimensions $10 \mu \mathrm{m}$ with medium height of $40 \mu \mathrm{m}$. From Figure $7 \mathrm{~b}$ it can be seen the morphology of PNEA coating was like to the globular structure with a growth of aggregates shaped as spherical grains. ${ }^{9,25-27,28-32}$

It can be remarked from Figure $7 \mathrm{c}-\mathrm{d}$ that the PPY-AOT/PNEA composite displayed that a uniform form of cauliflower structure with a small globulous microstructure ascribed adherent and compact over the Co67Cr29W4 alloy surface has been determined, which is comparable with the literature. The SEM image of the PPY-AOT/PNEA composite film deposited on Co67Cr29W4 alloy is homogeneous, powerful adherent over the Co67Cr29W4 alloy surface and the feature of the composite is so excellent. The dopant anionic surfactant sodium dioctyl sulfosuccinate sodium (AOT) incorporated into conducting polymers affect both electrodeposition process and also the characteristics of the achieved composite films. 


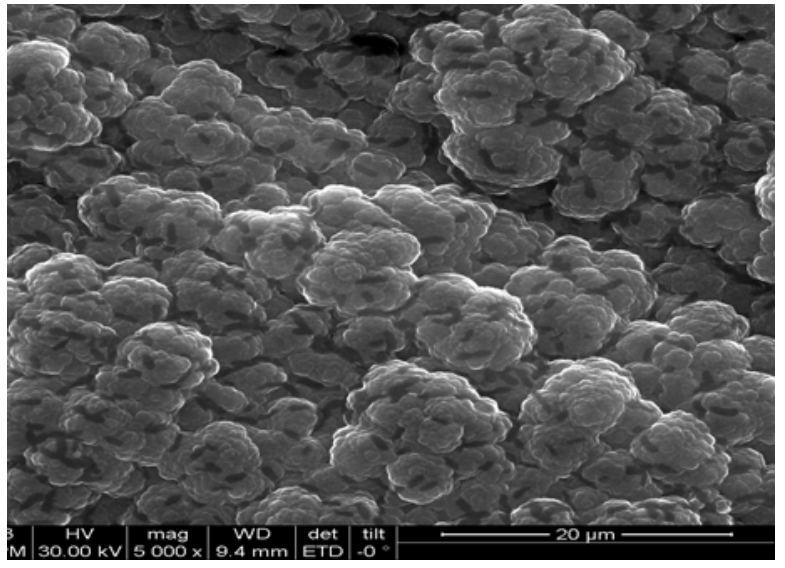

a) PPY-AOT

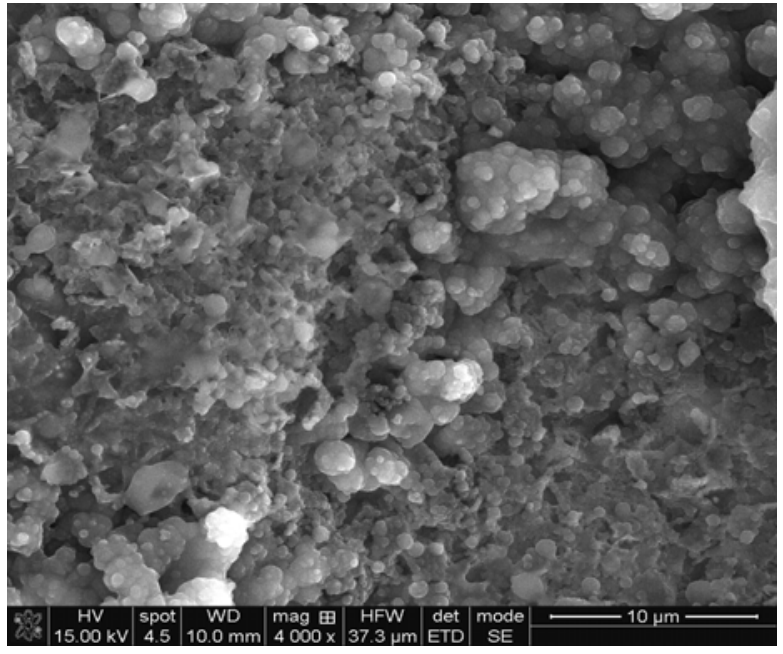

c) PPY-AOT/PNEA 5:4

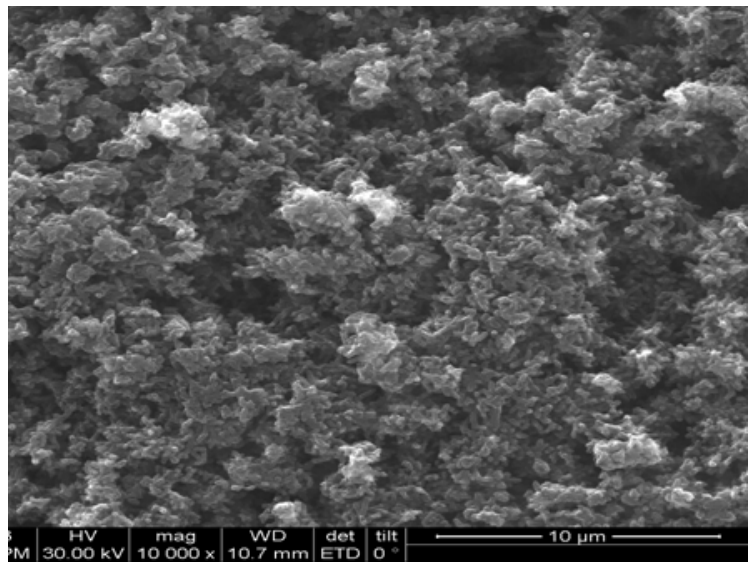

b) PNEA

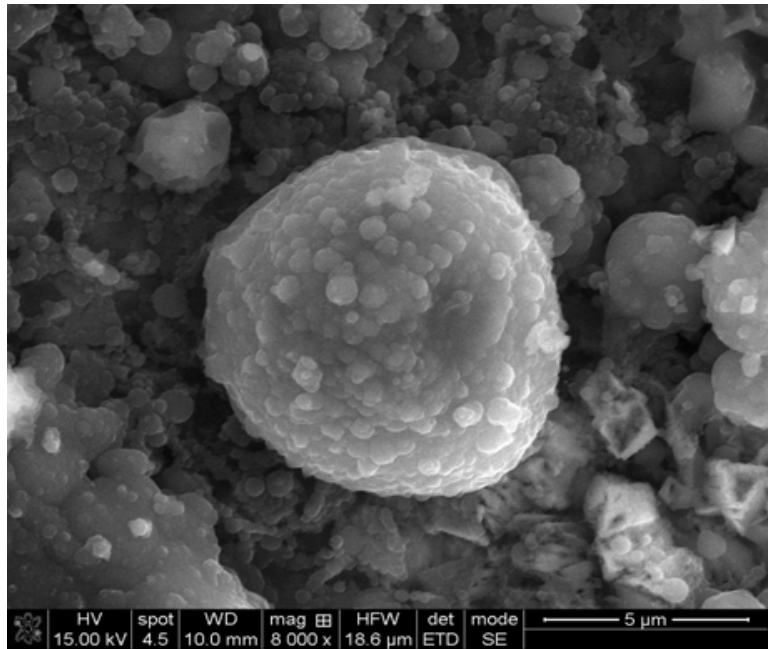

d) PPY-AOT/PNEA 3:5

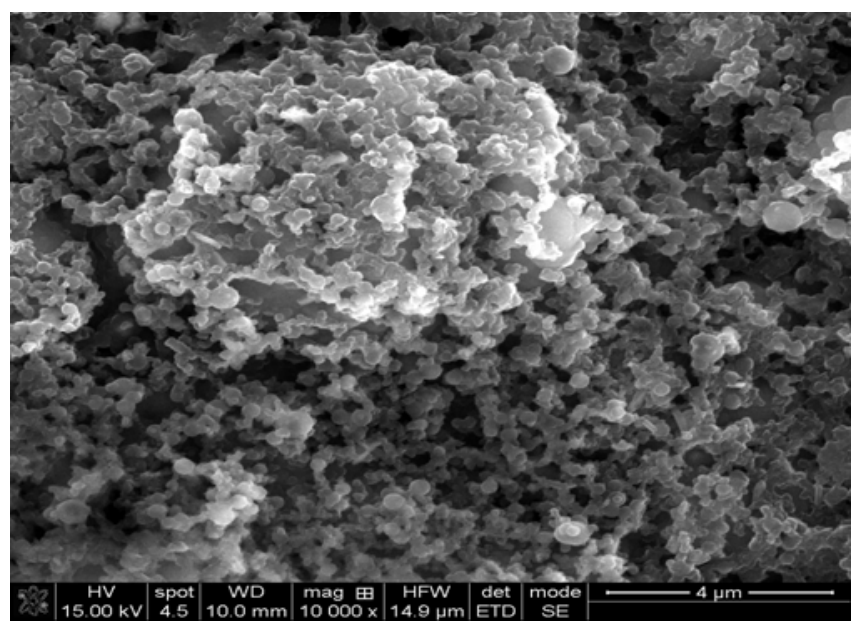

e) PPY-AOT/PNEA 5:5

Fig. 7 - The SEM micrographies of the (a) PPY-AOT, (b) PNEA and (c-d-e) PPY-AOT/PNEA composite films achieved by galvanostatic method after an electrodeposition time of $30 \mathrm{~min}$.

\section{CONCLUSIONS}

PPY-AOT, PNEA, PPY-AOT/PNEA composite films were successfully electrodeposited onto
Co67Cr29W4 alloy substrate by galvanostatic technique in different molar feed ratio of monomers and at different current densities from sulfuric acid solution. 
The constitution of PPY-AOT/PNEA composite film is realized by simultaneous oxidation and codeposition of N-ethyleaniline and pyrrole.

The voltammograms of the PPY and PNEA films indicates that the increasing of the number of cycles resulted in all the cases to the decrease of the anodic oxidation peak height and its displacement to a more positive potential.

This behaviour is owing to the establishment of a complex oxides film which prevents the redox processes of the polymeric film and so, the decrease of the anodic oxidation and the cathodic diminutions currents.

The electrochemical comportment of the composite films is influenced on the molar feed ratio of the monomers (N-ethyleaniline and pyrrole).

Nyquist and Bode diagrams are in good agreement with the results achieved by cyclic voltammetry.

The EIS diagram of the PPY-AOT/PNEA composite film demonstrates that the composite films are novel materials with various features in comparison with homopolymers.

The SEM micrographies of the PPY-AOT/PNEA composite films exhibited that a uniform form of cauliflower structure with a small globulous microstructure attributed adherent and compact over the Co67Cr29W4 alloy surface was determined.

The SEM image of the PPY-AOT/PNEA composite film deposited on Co67Cr29W4 alloy is homogeneous, powerful adherent over the Co67Cr29W4 alloy surface and the feature of the composite is so excellent.

PPY-AOT, PNEA, PPY-AOT/PNEA composite films were a very promising electrode material for application in supercapacitor, protection at corrosion or sensor employment.

\section{REFERENCES}

1. R. M. Metzer, C. A. Panetta, Y. Miura and E. Torres, Synth. Met., 1987, 18, 797.

2. C. F. Baes and R. E. Mesmer, "The Hydrolysis of Cation", Wiley, New York, 1976, p. 122.

3. L. Makaruk, A. Pron, Int. Polym. Sci. Technol., 1990, 17, 181.
4. F. Branzoi and V. Branzoi, Int. J. Polym. Mater. Polym. Biomater., 2014, 63, 549.

5. E. M. Genies and C. Tsintaris, J. Electroanal. Chem., 1988, 200, 127.

6. F. Branzoi, Open J. Org. Polym. Mater., 2015, 5, 89.

7. T. Kang, K. G. Neog and K. L. Tan, Prog. Polym. Sci., 1998, 23, 277.

8. S. Hung, T. Wen and A. Gopalan, Mater. Lett., 2002, 55, 165.

9. F. Branzoi, Z. Pahom and G. Nechifor, J. Adhesion Sci. Techn., 2018, 32, 2364.

10. E. M. Genies, G. Bidan and A. F. Diaz, J. Electroanal. Chem., 1983, 49, 101.

11. R. T. Lawson, Aust. J. Chem., 1994, 27, 105.

12. F. Branzoi, V. Branzoi and Z. Pahom, Rev. Roum. Chim., 2016, 61, 825 .

13. M. M. Lohrenged, Mater. Sci. Eng., 1993, R11, 243.

14. T. Osaka, K. Naoi, S. Ogano and S. Nakamura, J. Electrochem. Soc., 1987, 134, 2096.

15. H. Münstedt, G. Kohler, H. Mohwald, D. Naegele, R. Bitthin, G. Ely and E. Meissner, Synth. Met., 1987, 18, 259.

16. S. Panero, P. Prosperi and B. Scrosati, Electrochim. Acta, 1987, 32, 1465.

17. R. Noufi, D. Tench and L. F. Warren, J. Electrochem. Soc., 1980, 127, 1625.

18. J.-C. Lacroix, J.-L. Camalet, S. Aeiyach, K. I. ChaneChing, J. Petitjean, E. Chauveau and P.-C. Lacaze, J. Electroanal. Chem., 2000, 481, 76.

19. F. Branzoi, Z. Pahom and V. Branzoi, Rev. Roum. Chim., 2017, 62, 957.

20. F. Branzoi, V. Branzoi and Z. Pahom, Rev. Roum. Chim., 2013, 58, 49.

21. P. Ocón, A. B.Cristobal, P. Herrasti and E. Fatas, Corros. Sci., 2005, 47, 649.

22. M. B. González and S. B. Saidman, Corros. Sci., 2011, 53, 276.

23. V. Branzoi, F. Branzoi and L. Pilan, Mat. Chem. Phys., 2009, 118, 197.

24. N. O. Yagan, O. Pekmez and A. Yildiz, Prog. Org. Coat., 2007, 57, 314.

25. F. Branzoi and V. Branzoi, Int. J. Electrochem.Sci., 2016, 11,6564 .

26. C. K. Tan and D. J. Blackwood, Corros. Sci., 2003, 45, 545.

27. B. A. Abd-El-Naby, O. A. Abdullatef, E. Khamis and W. A. El-Mahmody, Int. J. Electrochem. Sci., 2016, 11, 1271.

28. R. Hasanov and S. Bilgic, Prog. Org. Coat, 2009, 64, 435.

29. B. Zeybek, N. O. Pekmez and E. Kilic, Electrochim Acta, 2011, 56, 9277.

30. F. Branzoi, V. Branzoi and A. Musina, Surface and Interface Analysis, 2012, 44, 1076.

31. F. Branzoi, V. Branzoi and A. Musina, Prog. Org. Coat., 2013, 76, 632 . 
